\title{
Short communication: Low-fat ice cream flavor not modified by high hydrostatic pressure treatment of whey protein concentrate
}

\author{
J. M. Chauhan, S.-Y. Lim, J. R. Powers, C. F. Ross, and S. Clark ${ }^{1}$ \\ Department of Food Science and Human Nutrition, lowa State University, Ames 50011-1061
}

\begin{abstract}
The purpose of this study was to examine flavor binding of high hydrostatic pressure (HHP)-treated whey protein concentrate (WPC) in a real food system. Fresh Washington State University (WSU, Pullman) WPC, produced by ultrafiltration of separated Cheddar cheese whey, was treated at $300 \mathrm{MPa}$ for $15 \mathrm{~min}$. Commercial WPC 35 powder was reconstituted to equivalent total solids as WSU WPC (8.23\%). Six batches of low-fat ice cream were produced: A) HHP-treated WSU WPC without diacetyl; B) and E) WSU WPC with $2 \mathrm{mg} / \mathrm{L}$ of diacetyl added before HHP; C) WSU WPC with 2 $\mathrm{mg} / \mathrm{L}$ of diacetyl added after HHP; D) untreated WSU WPC with $2 \mathrm{mg} / \mathrm{L}$ of diacetyl; and F) untreated commercial WPC 35 with $2 \mathrm{mg} / \mathrm{L}$ of diacetyl. The solution of WSU WPC or commercial WPC 35 contributed $10 \%$ to the mix formulation. Ice creams were produced by using standard ice cream ingredients and processes. Low-fat ice creams containing HHP-treated WSU WPC and untreated WSU WPC were analyzed using headspace-solid phase microextraction-gas chromatography. Sensory evaluation by balanced reference duotrio test was carried out using 50 untrained panelists in 2 sessions on 2 different days. The headspace-solid phase microextraction-gas chromatography analysis revealed that ice cream containing HHP-treated WSU WPC had almost 3 times the concentration of diacetyl compared with ice cream containing untreated WSU WPC at $d 1$ of storage. However, diacetyl was not detected in ice creams after $14 \mathrm{~d}$ of storage. Eighty percent of panelists were able to distinguish between low-fat ice creams containing untreated WSU WPC with and without diacetyl, confirming panelists' ability to detect diacetyl. However, panelists were not able to distinguish between low-fat ice creams containing untreated and HHP-treated WSU WPC with diacetyl. These results show that WPC diacetyl-binding properties were not enhanced by $300-\mathrm{MPa}$ HHP treatment for
\end{abstract}

Received September 1, 2009.

Accepted December 29, 2009.

${ }^{1}$ Corresponding author: milkmade@iastate.edu
15 min, indicating that HHP may not be suitable for such applications.

Key words: whey protein concentrate, high hydrostatic pressure, low-fat ice cream, flavor binding

\section{INTRODUCTION}

According to IDFA (2007), the average American per capita production of hard and soft low-fat and nonfat ice cream was 5.18 quarts in 2006, which was an increase of $5.3 \%$ over 2005 . In the same period of time, per capita production of regular hard and soft ice cream (12.9 quarts) increased by only 3.9\% (IDFA, 2007). However, producing high-quality reduced-fat dairy products is a challenge for manufacturers. As fat is lowered in foods, flavor challenges significantly increase because aroma compounds may be perceived as harsh and unbalanced (Hatchwell, 1994). Loss of flavor during processing and storage may be caused by increased volatility of flavor compounds (de Roos, 1997). Low-fat or reduced-fat products are less acceptable to consumers than their full-fat counterparts when measured by sensory analysis (Fulton and Hogbin, 1993; Charlton and Sawyer-Morse, 1996; Swanson, 1998). For example, fat increased the buttery and creamy notes as well as mouth coating in full-fat ice creams compared with low-fat ice cream (Koeferli et al., 1996). Full-fat ice creams also had higher flavor and texture ratings when measured by sensory analysis (Guinard and Marty, 1995). In one study, as fat content in chocolate ice cream decreased from $6.0 \%$ to $0.5 \%$, intense cocoa flavor with low creaminess, low smoothness, high chalkiness, and fast melting rate were observed, suggesting that fat provides physical barriers that slow the release of cocoa flavor volatiles into the vapor phase (Prindiville et al., 1999). Chung et al. (2003) also reported that fat strongly controlled the release of flavor volatiles during ice cream consumption. Adhikari et al. (2006) suggested that flavor manipulation in low-fat products to mimic the flavor release of full-fat products may enhance the richness of low-fat products.

Ice cream manufacturers use fat replacers to create products that meet market demand of consumers (Prindiville et al., 2000), but these products have not 
been totally successful. Fat has a unique functionality that enables it to react with flavor compounds and provide a pattern of flavor release in the mouth that no present fat replacer can provide (Yilsay et al., 2006). Carbohydrate-based fat replacers like inulin exerted a noticeable influence on the texture of low-fat ice cream but lowered flavor perception when measured using sensory analysis (Devereux et al., 2003). Much attention has been given to proteins in food systems because of their capability of influencing flavor binding and flavor release. Modified whey protein may be a good option for substitution of fat and binding of flavor (Liu et al., 2005a). $\beta$-Lactoglobulin and $\alpha$-LA, major proteins of whey protein, were reported to interact with many flavor compounds. $\beta$-Lactoglobulin interacted with aldehydes, ketones (O'Neill and Kinsella, 1988), and hydrophobic ligands, including retinal, fatty acids, alkanes, aliphatic ketones, and aromatic compounds (Perez and Calvo, 1995). $\alpha$-Lactabumin binds varying amounts of aldehydes and ketones (Kinsella, 1982). Whey protein concentrate (WPC) contains the largest number of binding sites for 2-nonanone and nonanal, with the strongest binding affinity of the proteins tested (Jasinski and Kilara, 1985). Whey protein concentrate also binds aliphatic aldehydes and methyl ketones (Ohmes et al., 1998). These observations have been mostly reported in terms of flavor binding of individual whey proteins, which protect, deliver, or delay release of flavor compounds. Whey proteins could be modified to carry a wide range of volatiles and reactive flavors in food system during processing or to release them in a more or less controlled manner (Boudaud and Dumont, 1996).

High hydrostatic pressure (HHP) has received attention as a process for food product modifications that is different from traditional processes that rely on heat (Patel et al., 2006). High hydrostatic pressure induces $\beta-L G$ into the molten globule state, a protein structural conformation intermediate between the ordered native and fully unfolded denatured state of protein (Yang et al., 2001). Proteins in the molten globule state exhibit unique hydrophobic structure with increased surface hydrophobicity, resulting in increased binding sites for flavor compounds (Ptitsyn and Semisotnov, 1991). Molten globule $\beta$-LG exhibited a 3 -fold increase of 1-anilino-naphthalene-8-sulfonate (ANS) fluorescence ligand binding intensity, indicating potential for improvement in flavor binding and flavor release during consumption (Yang et al., 2001; Liu et al., 2005b). The $\beta$-LG binding sites for flavor compounds may be more accessible in the molten globule state than in the native state (Yang et al., 2001).

Protein binding of flavor compounds is associated with hydrophobic interaction (O'Neill and Kinsella,
1987; Damodaran, 1989; Fischer and Widder, 1997) and has been studied by different techniques (Damodaran and Kinsella, 1980; O'Neill and Kinsella, 1988, Andriot et al., 2000). Steam distillation, simultaneous distillation extraction, static headspace (HS), and dynamic HS have been used to study the volatile compounds in dairy products (Lee et al., 2003). In HS analysis, measurement of volatile compounds in the gaseous HS above food samples estimates binding and release of flavor compounds (Damodaran and Kinsella, 1980; Kinsella, 1990; Rega et al., 2003). Solid-phase microextraction (SPME) is a solvent-free method of extracting analytes from a variety of matrices by partitioning them from a liquid or gaseous sample onto an immobilized stationary phase. These compounds are then desorbed and analyzed using GC. This technique has been developed to combine sampling and sample preparation in 1 step (Wardencki et al., 2004). Head space analysis is a sensitive method, often used for the quantitative analysis of flavor and fragrance compounds (Hawthorne et al., 1992; Zhang and Pawliszyn, 1993). Solid-phase microextraction has been used to analyze the volatile compounds of ewe's milk cheese (Pinho et al., 2003), Cheddar cheese, Swiss cheese, Parmesan cheese (Lee et al., 2003), Cheddar cheese whey (Carunchia Whetstine et al., 2003), and whey protein isolates (Carunchia Whetstine et al., 2005; Wright et al., 2006).

This research was conducted to determine the ability of consumers to note differences among low-fat ice creams containing HHP-treated and untreated fresh WPC, with and without diacetyl. The objective was to investigate the binding properties of WPC for diacetyl and the potential for HHP applications in lowfat ice cream. Diacetyl (2,3-butanedione) was selected because it contributes a characteristic buttery aroma and dairy complexity to the sensory quality of food (Collins, 1972). Although diacetyl is one of the most predominant flavors in dairy products, little work had been done in analyzing it because of its high volatility and difficulty of analysis. Additionally, little work has been done regarding the effects of HHP on flavor binding properties of WPC and applications in a real food system. Headspace SPME was selected for analysis because of the high volatility of the analytes (Hayasaka and Bartowsky, 1999); the HS method reduces matrix effects and any interference from other constituents. In this study, 1-pentanol was used as an internal standard because of its use for flavor analysis of whey proteins in previous research (Carunchia Whetstine et al., 2003). The olfactory threshold for diacetyl has been reported to be $5 \mathrm{mg} / \mathrm{L}$ (Lawless, 1994), $8.6 \mathrm{mg} / \mathrm{L}$ in aqueous solution (Pietrzak and Barylko-Pikielna, 1976), $10 \mathrm{mg} / \mathrm{L}$ in skim milk (Bennett, 1973), and $29 \mathrm{mg} / \mathrm{L}$ in homogenized milk (Reddy et al., 1969). Tuorila et al. (1995) 
found slightly lower values for aqueous odor detection thresholds, ranging from 0.3 to $0.9 \mathrm{mg} / \mathrm{L}$ depending on the sensory method employed. In the present study, a concentration of $2 \mathrm{mg} / \mathrm{L}$ was added to WPC because it was considered an intermediate level based on previous research.

\section{MATERIALS AND METHODS}

Separated Cheddar cheese whey was collected, pasteurized, concentrated by ultrafiltration, and HHPtreated according to Lim et al. (2008a). The pasteurized Washington State University (WSU) WPC was pressurized immediately or stored at $4^{\circ} \mathrm{C}$ for less than $2 \mathrm{wk}$ until pressurization, cooled to $4^{\circ} \mathrm{C}$, and used the next day to produce low-fat ice cream. Low-fat ice creams (six 34-kg batches) were produced one time per each batch, as reported by Lim et al. (2008a), except for the content of WSU WPC, and/or presence of diacetyl. Specifically, mix A contained HHP-treated WSU WPC without diacetyl; mix B and mix E were made on separate days and contained HHP-treated WSU WPC with diacetyl (Sigma Aldrich, Allentown, PA) added before HHP treatment; mix C contained HHP-treated WSU WPC with diacetyl added after HHP treatment; mix D contained untreated WSU WPC with diacetyl; and mix F contained commercially available WPC 35 (Foremost Farms, Clayton, WI) with diacetyl. All mixes with diacetyl added had $2 \mathrm{mg} / \mathrm{L}$. The 6 batches of ice cream mix were pasteurized using a universal pilot plant system (Processing Machinery and Supply Co., Philadelphia, PA) with continuous plate heat exchanger to at least $65^{\circ} \mathrm{C}$ for $30 \mathrm{~s}$ holding time. The mixes were homogenized (Lab 60, Gaulin GmbH, Lubeck, Germany) at $3,447 \mathrm{kPa}$ in the second stage and $17,237 \mathrm{kPa}$ in the first stage. To avoid variation in mixes, 3 batches were made on the same day, whereas the other 3 were made on another day. Each mix was aged for $12 \mathrm{~h}$ at $4^{\circ} \mathrm{C}$ before freezing. The mixes were frozen using a continuous freezer (Technogel 100, Bergumo, Italy) for a desired overrun of $67 \%$, which was best achieved by the freezer used. After freezing, ice cream was collected into 1-pint (473-mL) containers and placed in a hardening freezer at $-25^{\circ} \mathrm{C}$ for storage until analysis.

A manual SPME fiber holding unit and a polydimethylsiloxane/divinylbenzene fiber $(65-\mu \mathrm{m}$ diameter) were from Supelco Inc. (Bellefonte, PA). The fiber was selected based on its affinity for diacetyl and the symmetry of chromatographic peaks. The 15-mL amber glass vials, Teflon-coated rubber septa, magnetic stirrer, and polyethylene caps were also from Supelco Inc. The fiber was conditioned according to the manufacturer's instructions. For each extraction, $0.1 \mathrm{~mL}$ of 1 -pentanol (2 mg/L; Milli-Q demineralized water, Millipore, Bedford,
MA) as the internal standard and $1.4 \mathrm{~g}$ of $\mathrm{NaCl} / 5.0 \mathrm{~g}$ of low-fat ice cream were placed in a $15-\mathrm{mL}$ amber glass vial. The vial was placed on a magnetic hot stir plate (model PC-220, Corning Inc., Corning, NY) and stirred at $400 \mathrm{rpm}$ for $5 \mathrm{~min}$ to preequilibrate volatiles at $37^{\circ} \mathrm{C}$. The content of the vial was continuously stirred during adsorption and temperature was maintained at $37^{\circ} \mathrm{C}$. For extraction, the SPME fiber was exposed to the HS of the solution for $10 \mathrm{~min}$ to adsorb the analytes. After $10 \mathrm{~min}$, the fiber was withdrawn into the fiber assembly and then introduced into a heated chromatograph injector for desorption and analysis. All the samples were analyzed in triplicate.

The analysis was performed in a Hewlett-Packard HP 5890A gas chromatograph (Hewlett-Packard, Palo Alto, CA) connected to a flame ionization detector with a split/splitless injector and SPME liner. A DB-WAX column $(60 \mathrm{~m} \times 0.32 \mathrm{~mm}$ i.d., $0.5 \mu \mathrm{m}$ film thickness; $\mathrm{J} \& \mathrm{~W}$ Scientific, Folsom, CA) was used. All injections were made in splitless mode and the SPME fiber was exposed inside the injector for $1 \mathrm{~min}$. The injector temperature was maintained at $200^{\circ} \mathrm{C}$ and the detector at $250^{\circ} \mathrm{C}$. Helium was used as the carrier gas. The oven temperature was initially $33^{\circ} \mathrm{C}(5 \mathrm{~min})$, then increased at a rate of $2^{\circ} \mathrm{C} / \mathrm{min}$ to $50^{\circ} \mathrm{C}$, then increased at a rate of $15^{\circ} \mathrm{C} / \mathrm{min}$ to $200^{\circ} \mathrm{C}$, and was then held for $10 \mathrm{~min}$.

A standard curve to ensure linearity of response for HS-SPME was prepared using standard concentrations of 1-pentanol (internal standard; 1.0, 2.0, and 4.0 $\mathrm{mg} / \mathrm{L})$ and diacetyl $(0.5,1.0,2.0$, and $4.0 \mathrm{mg} / \mathrm{L})$ in demineralized Milli-Q filtered water (Millipore). For standard curve preparation, $5 \mathrm{~mL}$ of the appropriate standard solution of either diacetyl or 1-pentanol and $1.4 \mathrm{~g}$ of $\mathrm{NaCl}$ were added to a $15-\mathrm{mL}$ amber vial. Volatile compounds in the vial HS were adsorbed using HS-SPME for $10 \mathrm{~min}$ at $37^{\circ} \mathrm{C}$, and a calibration curve was prepared by plotting peak area against solution concentration of specific compounds. Means of triplicate analyses of diacetyl concentration were analyzed by ANOVA using Microsoft Excel (2003 version, Microsoft Inc., Redmond, WA), and $P \leq 0.05$ was defined as a significant difference.

Fifty students and employees of WSU evaluated low-fat vanilla ice cream in private booths using Compusense Five (release 4.6, Compusense Inc., Guelph, Ontario, Canada) on 2 different days. Before serving, all cups containing 1 scoop of ice cream (about $30 \mathrm{~g}$ ) were put in a freezer to temper to about $-10^{\circ} \mathrm{C}$. The balanced reference duo-trio test was used to determine consumer ability to distinguish differences between samples. Panelists were served 3 flights of samples per session. In each flight, one sample was identical to the reference and one was different. Panelists were asked to identify the sample that was the same as the reference. 
Table 1. Diacetyl concentration $(\mathrm{mg} / \mathrm{L})$ in low-fat ice cream containing untreated Washington State University (WSU) whey protein concentrate (WPC) and low-fat ice cream containing high hydrostatic pressure (HHP)treated WSU WPC after 1,7 , and $14 \mathrm{~d}$ of storage at $-25^{\circ} \mathrm{C}$

\begin{tabular}{lccc}
\hline Low-fat ice cream & Day 1 & Day 7 & Day 14 \\
\hline A (untreated WSU WPC) & $0.3174 \pm 0.133^{\mathrm{a}}$ & $0.1610 \pm 0.074^{\mathrm{c}}$ & $\mathrm{ND}^{1}$ \\
B (HHP-treated WSU WPC) & $1.0084 \pm 0.114^{\mathrm{b}}$ & $0.5333 \pm 0.098^{\mathrm{d}}$ & $\mathrm{ND}^{\mathrm{a}}$ \\
\hline${ }^{\mathrm{a}-\mathrm{d}}$ Different letters within columns indicate significant difference as determined by Fisher's LSD $(P<0.05)$. \\
${ }^{1} \mathrm{ND}=$ not detected.
\end{tabular}

Panelists were also asked to include comments on the flavor of low-fat ice cream after each set of samples. Serving order was randomized and samples were blindcoded using random 3-digit code numbers (Lim et al., $2008 \mathrm{~b}$ ). Water was provided for palate cleansing between samples because retronasal evaluation (tasting), instead of orthonasal evaluation (sniffing), was used to detect diacetyl. Data were analyzed by Compusense Five (release 4.6).

\section{RESULTS AND DISCUSSION}

Diacetyl recovery from low-fat ice creams using HSSPME analysis is presented in Table 1 . At storage d 1 (control; $t=0$ ), diacetyl concentration in low-fat ice cream containing HHP-treated WSU WPC (1.0084 $\mathrm{mg} / \mathrm{L}$ ) was more than 3 times greater than in low-fat ice cream containing untreated WSU WPC $(0.3174 \mathrm{mg} / \mathrm{L})$. This result indicates the greater binding of diacetyl by HHP-treated WSU WPC than that of untreated WSU WPC because diacetyl is hydrophilic and HHP treatment leads to enhanced hydrophobicity of whey proteins. The result suggests that the HHP treatment of WSU WPC at $300 \mathrm{MPa}$ for 15 min increased the diacetyl binding affinity, which confirmed the previous report of increased diacetyl binding affinity of WPC when subjected to HHP treatment of $300 \mathrm{MPa}$ for 10 min (Liu et al., 2005a). The volatility of flavor compounds is decreased in the presence of WPC, mainly because of hydrophobic interactions of flavors with proteins in WPC (Guichard and Langorieux, 2000). However, many researchers have reported an increase in flavor retention in the presence of whey proteins (Guichard and Langorieux, 2000). The initial retention of diacetyl in low-fat ice cream containing HHP-treated WSU WPC was consistent with previous research in which benzaldehyde and methyl ketones were used as flavors in a whey protein $\beta$-LG solution (Liu et al., $2005 \mathrm{a})$. The addition of $\beta$-LG reduced the perception of methyl ketones in aqueous solutions and increased the retention of methyl ketones (Andriot et al., 2000).

Although the concentration of diacetyl in the headspace of low-fat ice cream containing HHP-treated WSU WPC was higher than in low-fat ice cream with untreat- ed WSU WPC after $7 \mathrm{~d}$ of storage, the level of diacetyl decreased to almost half that measured on $\mathrm{d} 1$. One explanation for this change may be that diacetyl, which is hydrophilic, very soluble in water, and released very quickly from water because of its volatility (Adhikari et al., 2006), simply evaporated from the water phase of ice cream during frozen storage. Another explanation may be attributed to protein conformational changes. Lee et al. (1995) postulated conformational changes to proteins that decrease binding sites on protein, increase interactions between proteins, and may reduce diacetyl headspace concentration. The decrease of diacetyl retention could be attributed to conformational changes of whey proteins or the formation of aggregates under extreme temperature storage conditions, and to decreased binding affinity of protein for diacetyl (Lee et al., 1995). At storage d 14, diacetyl was absent in HS of low-fat ice cream with added diacetyl, showing that HHP treatment increased binding of diacetyl in WSU WPC initially, but the strength of the binding was not enough to bind for $14 \mathrm{~d}$.

The results from sensory evaluation of 3 low-fat ice creams for the first session are summarized in Table 2. When ice cream samples had been stored for $3 \mathrm{~d}$, panelists $(\mathrm{n}=50)$ were able to correctly distinguish ice cream with added diacetyl from ice cream without diacetyl. This finding confirms that diacetyl, when added at a level of only $2 \mathrm{mg} / \mathrm{L}$ to low-fat ice cream, was detected by panelists; diacetyl did not evaporate to a degree that made its sensory detection impossible irrespective of the condition or time of addition of diacetyl to WSU WPC. Additionally, the suggestion of Tuorila et al. (1995) that threshold values for aqueous diacetyl odor $(0.3-0.9 \mathrm{mg} / \mathrm{L})$ are lower than other investigators suggested is supported because our instrumental measurements for diacetyl on d 1 ranged from only 0.3 to 1 . More than $60 \%$ of panelists commented on the creamy/ buttery flavor of the ice cream and liked the flavor. Panelists could not distinguish between diacetyl additions to WSU WPC before or after HHP treatment, which indicates that addition of diacetyl to WPC before or after HHP should not have practical implications.

The results from sensory analysis of the second set of 3 low-fat ice creams are summarized in Table 3. Pan- 
Table 2. Results of sensory analysis $(\mathrm{n}=50)$ of low-fat ice creams using balanced reference duo-trio tests

\begin{tabular}{lcccc}
\hline Ice cream $^{1}$ & Correct guess $(\mathrm{n})$ & Incorrect guess $(\mathrm{n})$ & Confidence & Significance $(P$-value $)$ \\
\hline A vs. B & 40 & 10 & 1.000 & $0.000^{*}$ \\
B vs. C & 26 & 24 & 0.556 & $0.444(P>0.05)$ \\
A vs. C & 40 & 10 & 1.000 & $0.000^{*}$ \\
\hline
\end{tabular}

${ }^{1}$ Ice cream samples: A = high hydrostatic pressure (HHP)-treated Washington State University (WSU) whey protein concentrate $(\mathrm{WPC})$, no diacetyl; $\mathrm{B}=$ HHP-treated WSU WPC with diacetyl added before HHP treatment; $\mathrm{C}=$ HHP-treated WSU WPC with diacetyl added after HHP treatment.

$* P<0.05$.

elists $(\mathrm{n}=52)$ were not able to distinguish between low-fat ice creams containing HHP-treated WSU WPC with diacetyl and ice cream containing untreated WSU WPC with diacetyl. This finding indicates that HHP treatment did not modify flavor-binding properties of WPC to an extent that could be detected by panelists in a food system. In the past, researchers have used WPC and whey protein-based fat replacers in low-fat ice cream that induced differences mainly in rheological properties like body and texture, melting, and color (Roland et al., 1999; Ruger et al., 2002). High hydrostatic pressure-treated WSU WPC also yielded improved foam stability and hardness of low-fat ice cream (Lim et al., 2008b). There is no evidence in the present study nor in past studies to show that flavor binding of HHP-treated WPC improved product quality. Although panelists were able to successfully distinguish between low-fat ice cream containing HHP-treated WSU WPC with diacetyl and untreated commercial WPC 35 with diacetyl, their comments indicated that something other than flavor differed between WPC 35 and HHP-treated WSU WPC, which enabled panelists to distinguish the products. Indeed, research in our laboratory showed that body and texture characteristics differentiated similar test samples (Lim et al., 2008b).

Release of flavor compounds from food during consumption is a key quality parameter in food and beverages (Haahr et al., 2000). To elicit a response, a flavor compound must achieve a sufficient concentration in the nasal cavity (vapor phase) or saliva (aqueous phase) to stimulate the olfactory or taste receptors, respectively (Kinsella, 1990). Concentration of flavor compounds and flavor perception during consumption of food depend on the nature and concentration of the volatiles present in the food as well as on their availability for perception (Harrison and Hills, 1997). The rate of flavor release from the food matrix and the persistence of flavor volatiles in the olfactory system depend on physicochemical properties of flavor compounds, such as volatility and hydrophobicity (Harrison et al., 1997; Deibler et al., 2001). Availability of a flavor compound is influenced mainly by the interaction of the flavor compound and nonvolatile food constituents, such as fat, proteins, and carbohydrates (Bakker and Mela, 1996). Even in similar food matrices, differences in physical properties like viscosity (Yven et al., 1998), matrix deformation (Guinard and Marty, 1995; Taylor, 1996), and melting point (Lee and Pangborn, 1986) will lead to different release behavior of flavor volatiles during food consumption. High hydrostatic pressure treatment affects flavor-binding of fresh WPC, as shown by initial evidence of diacetyl in low-fat ice cream by HS-SPME analysis. The amount of volatiles released from a food matrix is influenced by many aspects of the flavor compounds, such as vapor pressure, solubility, concentration, and release between air and liquid phases, and interactions with other food constituents (Kinsella, 1990; Landy et al., 1996). However, HHP treatment of WPC at $300 \mathrm{MPa}$ for $15 \mathrm{~min}$ did not significantly improve binding properties of WPC for diacetyl such that an effect was noted when WPC was used at a level of $10 \%$ in ice cream.

Table 3. Results of sensory analysis $(n=52)$ of low-fat ice creams using balanced reference duo-trio tests

\begin{tabular}{lcccc}
\hline Ice cream $^{1}$ & Correct guess $(\mathrm{n})$ & Incorrect guess $(\mathrm{n})$ & Confidence & Significance $(P$-value $)$ \\
\hline D vs. E & 22 & 30 & 0.106 & $0.894(P>0.05)$ \\
E vs. F & 37 & 15 & 0.998 & $0.002^{*}$ \\
D vs. F & 25 & 27 & 0.339 & $0.661(P>0.05)$ \\
\hline
\end{tabular}

${ }^{1}$ Ice cream samples: $\mathrm{D}=$ untreated Washington State University (WSU) whey protein concentrate (WPC) with added diacetyl; $\mathrm{E}=$ high hydrostatic pressure (HHP)-treated WSU WPC with diacetyl added after HHP treatment; $\mathrm{F}=$ untreated commercial WSU 35 with added diacetyl.

${ }^{*} P<0.05$. 


\section{CONCLUSIONS}

Ice cream is complex, and only $10 \%$ WPC composed each low-fat product in the present study. Thus, the pure effects of WPC-diacetyl binding may have been masked by other ingredients or physical properties. To better understand the effect of HHP on flavor binding properties of WPC in real food application, appropriate flavor, concentration, WPC treatment, and suitable food system should be selected.

\section{ACKNOWLEDGMENTS}

This research was funded by Washington State Dairy Products Commission (Seattle, WA). Special thanks are given to Foremost Farms (Baraboo, WI) for supplying ingredients and to Frank Younce (Washington State University) and the Washington State University Creamery staff for assisting with this research.

\section{REFERENCES}

Adhikari, K., K. A. Hein, J. R. Elmore, H. Heyman, and A. M. Willott. 2006. Flavor threshold as affected by interaction among three dairy-related flavor compounds. J. Sens. Stud. 21:626-643.

Andriot, I., M. Harrison, N. Fournier, and E. Guichard. 2000. Interactions between methyl ketones and beta-lactoglobulin: Sensory analysis, headspace analysis, and mathematical modeling. J. Agric. Food Chem. 48:4246-4251.

Bakker, J., and D. J. Mela. 1996. Effect of emulsion structure on flavor release and taste perception. Pages 36-47 in Flavor-Food Interactions. R. J. McGorrin, and J. V. Leland, ed. ACS Symposium Series 633. American Chemical Society, Washington, DC.

Bennett, G., B. J. Liska, and W. L. Hempenius. 1973. Effect of other flavor components on the perception of diacetyl in fermented dairy products. J. Food Sci. 30:35-37.

Boudaud, N., and J. P. Dumont. 1996. Interaction between flavor components and beta-lactoglobulin. Pages $90-108$ in Flavor-Food interactions. R. J. McGorrin, and J. V. Leland, ed. ACS Symposium Series 633. American Chemical Society, Washington, DC.

Carunchia Whetstine, M. E., A. E. Croissant, and M. A. Drake. 2005. Characterization of dried whey protein concentrate and isolate flavor. J. Dairy Sci. 88:3826-3839.

Carunchia Whetstine, M. E., J. D. Parker, M. A. Drake, and D. K. Larick. 2003. Determining flavor and flavor variability in commercially produced liquid Cheddar whey. J. Dairy Sci. 86:439-448.

Charlton, O., and M. K. Sawyer-Morse. 1996. Effect of fat replacement on sensory attributes of chocolate chip cookies. J. Am. Diet. Assoc. 96:1288-1290.

Chung, S. J., H. Heymann, and I. U. Gruen. 2003. Temporal release of flavor compounds from low fat and high fat ice cream during eating. J. Food Sci. 68:2150-2156.

Collins, E. B. 1972. Biosynthesis of flavor compounds by microorganisms. J. Dairy Sci. 55:1022-1028.

Damodaran, S. 1989. Interrelationship of molecular and functional properties of food proteins. Pages $21-51$ in Food Proteins. W. G. Soucie and J. E. Kinsella, ed. American Oil Chemists' Society, Champaign, IL.

Damodaran, S., and J. E. Kinsella. 1980. Flavor protein interactions. Binding of carbonyls to bovine serum albumin: Thermodynamic and conformational effects. J. Agric. Food Chem. 28:567-571.

de Roos, K. B. 1997. How lipids influence food flavor. Food Technol. 51:60-63.
Deibler, K. D., E. H. Lavin, R. S. T. Linforth, A. J. Taylor, and T. E. Acree. 2001. Verification of a mouth simulator by in vivo measurements. J. Agric. Food Chem. 49:1388-1393.

Devereux, H. M., G. P. John, L. McCormack, and W. C. Hunter. 2003. Consumer acceptability of low fat foods containing inulin and oligofructose. J. Food Sci. 68:1850-1854.

Fischer, N., and S. Widder. 1997. How proteins influence food flavor. Food Technol. 51:68-70.

Fulton, L., and M. Hogbin. 1993. Eating quality of muffins, cake, and cookies prepared with reduced fat and sugar. J. Am. Diet. Assoc. 93:1313-1316.

Guichard, E., and S. Langorieux. 2000. Interactions between betalactoglobulin and flavor compounds. Food Chem. 71:301-308.

Guinard, J. X., and C. Marty. 1995. Time-intensity measurement of flavor release from a model gel system: Effect of gelling agent type and concentration. J. Food Sci. 60:727-730.

Haahr, A. M., W. L. P. Bredie, L. H. Stahnke, B. Jensen, and H. H. F. Refsgaard. 2000. Flavor release of aldehydes and diacetyl in oil/ water systems. Food Chem. 71:355-362.

Harrison, M., and B. P. Hills. 1997. Mathematical model of flavor release from liquids containing aroma-binding macromolecules. J. Agric. Food Chem. 45:1883-1890.

Harrison, M., B. P. Hills, J. Bakker, and T. Clothier. 1997. Mathematical models of flavor release from liquid emulsions. J. Food Sci. 62:653-658.

Hatchwell, L. C. 1994. Overcoming flavor challenges in low-fat frozen desserts. Food Technol. 48:98-100,102

Hawthorne, S. B., D. J. Miller, J. Pawliszyn, and C. L. Arthur. 1992. Solventless determination of caffeine in beverages using solidphase microextraction with fused-silica fibers. J. Chromatogr. A 603:185-191.

Hayasaka, Y., and E. J. Bartowsky. 1999. Analysis of diacetyl in wine using solid-phase microextraction combined with gas chromatography-mass spectrometry. J. Agric. Food Chem. 47:612-617.

IDFA. 2007. International Dairy Foods Association, Milk Industry Foundation, National Cheese Institute, International Ice Cream Association, Dairy Foods magazine: Dairy Facts 2007 Edition. International Dairy Foods Association, Washington, DC.

Jasinski, E., and A. Kilara. 1985. Flavor binding by whey proteins. Milchwissenschaft 40:596-599.

Kinsella, J. E. 1982. Protein structure and functional properties: Emulsification and flavor binding effects. Pages 301-326 in Food Protein Deterioration: Mechanism and Functionality. J. P. Cherry, ed. Am. Chem. Soc., Washington, DC.

Kinsella, J. E. 1990. Flavor perception and binding. International news on fats, oils and related materials. Inform 1:215-226.

Koeferli, C. R. S., P. Piccinali, and S. Sigrist. 1996. The influence of fat, sugar and non-fat milk solids on selected taste, flavor and texture parameters of a vanilla ice-cream. Food Qual. Prefer. 7:69-79.

Landy, P., J. L. Courthaudon, C. Dubois, and A. Voilley. 1996. Effect of interface in model food emulsions on the volatility of aroma compounds. J. Agric. Food Chem. 44:526-530.

Lawless, H. T. 1994. Getting results you can trust from sensory evaluation. Cereal Food World 39:809-814.

Lee, J. H., R. Diono, G. Y. Kim, and D. B. Min. 2003. Optimization of solid phase microextraction analysis for the headspace volatile compounds of Parmesan cheese. J. Agric. Food Chem. 51:11361140 .

Lee, K. D., C. G. Lo, R. L. Richter, and C. W. Dill. 1995. Effect of milk composition on the partition coefficients of diacetyl, acetaldehyde, and ethanol in acidified milk products. J. Dairy Sci. 78:2666-2674.

Lee, W. E. III, and R. M. Pangborn. 1986. Time-intensity: The temporal aspects of sensory perception. Food Technol. 40:71-78., 82 .

Lim, S.-Y., B. G. Swanson, and S. Clark. 2008a. High hydrostatic pressure modification of whey protein concentrate for improved functional properties. J. Dairy Sci. 91:1299-1307.

Lim, S.-Y., B. G. Swanson, C. F. Ross, and S. Clark. 2008b. High hydrostatic pressure modification of whey protein concentrate for 
improved body and texture of low-fat ice cream. J. Dairy Sci. 91:1308-1316.

Liu, X., J. R. Powers, B. G. Swanson, H. H. Hill, and S. Clark. 2005a. High hydrostatic pressure affects flavor-binding properties of whey protein concentrate. J. Food Sci. 70:C581-C585.

Liu, X., J. R. Powers, B. G. Swanson, H. H. Hill, and S. Clark. 2005b. Modification of whey protein concentrate hydrophobicity by high hydrostatic pressure. Innov. Food Sci. Emerg. Technol. 6:310317.

O'Neill, T. E., and J. E. Kinsella. 1987. Binding of alkanone flavors to beta-lactoglobulin: Effects of conformational and chemical modification. J. Agric. Food Chem. 35:770-774.

O'Neill, T. E., and J. E. Kinsella. 1988. Effect of heat treatment and modification on conformation and flavor binding by betalactoglobulin. J. Food Sci. 53:906-909.

Ohmes, R. L., R. T. Marshall, and H. Heymann. 1998. Sensory and physical properties of ice creams containing milk fat or fat replacers. J. Dairy Sci. 81:1222-1228.

Patel, H. A., H. Singh, S. G. Anema, and L. K. Creamer. 2006. Effects of heat and high hydrostatic pressure treatments on disulfide bonding interchanges among the proteins in skim milk. J. Agric. Food Chem. 54:3409-3420.

Pérez, M. D., and M. Calvo. 1995. Interaction of beta-lactoglobulin with retinol and fatty acids and its role as a possible biological function for this protein: A review. J. Dairy Sci. 78:978-988.

Pietrzak, E., and N. Barylko-Pikielna. 1976. Determination of odour absolute threshold of some sulphur compounds . Acta Aliment Pol. 2:207-212.

Pinho, O., I. M. P. L. V. O. Ferreira, and M. A. Ferreira. 2003. Quantification of short-chain free fatty acids in "Terrincho" ewe cheese: Intravarietal comparison. J. Dairy Sci. 86:3102-3109.

Prindiville, E. A., R. T. Marshall, and H. Heymann. 1999. Effect of milk fat on the sensory properties of chocolate ice cream. J. Dairy Sci. 82:1425-1432.

Prindiville, E. A., R. T. Marshall, and H. Heymann. 2000. Effect of milk fat, cocoa butter, and whey protein fat replacers on the sensory properties of low-fat and nonfat chocolate ice cream. J. Dairy Sci. 83:2216-2223.

Ptitsyn, O. B., and G. V. Semisotnov. 1991. The mechanism of protein folding. Pages 155-168 in Conformations and Forces in Protein
Folding. T. N. Barry and A. D. Ken, ed. American Association for the Advancement of Science, Washington, DC.

Reddy, M. C., R. C. Lindsay, and D. D. Bills. 1969. Ester production by Pseudomonas fragi. III. Synergistic flavor interaction of esters at subthreshold concentrations. J. Dairy Sci. 52:1198-1201.

Rega, B., N. Fournier, and E. Guichard. 2003. Solid phase microextraction (SPME) of orange juice flavor: Odor representativeness by direct gas chromatography olfactometry (D-GC-O). J. Agric. Food Chem. 51:7092-7099.

Roland, A. M., L. G. Phillips, and K. J. Boor. 1999. Effects of fat replacers on the sensory properties, color, melting, and hardness of ice cream. J. Dairy Sci. 82:2094-2100.

Ruger, P. R., R. J. Baer, and K. M. Kasperson. 2002. Effect of double homogenization and whey protein concentrate on the texture of ice cream. J. Dairy Sci. 85:1684-1692.

Swanson, R. B. 1998. Acceptability of reduced-fat peanut butter cookies by school nutrition managers. J. Am. Diet. Assoc. 98:910-912.

Taylor, A. J. 1996. Volatile flavor release from foods during eating. Crit. Rev. Food Sci. Nutr. 36:765-784.

Tuorila, H., C. Sommardahl, L. Hyvonen, K. Leporanta, and P. Merimaa. 1995. Does fat affect the timing of flavor perception? A case study with yogurt. Food Qual. Prefer. 6:55-58.

Wardencki, W., M. Michulec, and J. Curylo. 2004. A review of theoretical and practical aspects of solid-phase microextraction in food analysis. Int. J. Food Sci. Technol. 39:703-717.

Wright, J. M., M. E. Carunchia Whetstine, R. E. Miracle, and M. Drake. 2006. Characterization of a cabbage off-flavor in whey protein isolate. J. Food Sci. 71:C86-C90.

Yang, J., A. K. Dunker, J. R. Powers, S. Clark, and B. G. Swanson. 2001. $\beta$-Lactoglobulin molten globule induced by high pressure. J. Agric. Food Chem. 49:3236-3243.

Yilsay, T. Ö., L. Yilmaz, and A. A. Bayizit. 2006. The effect of using a whey protein fat replacer on textural and sensory characteristics of low-fat vanilla ice cream. Eur. Food Res. Technol. 222:171-175.

Yven, C., E. Guichard, A. Giboreau, and D. D. Roberts. 1998. Assessment of interactions between hydrocolloids and flavor compounds by sensory, headspace, and binding methodologies. J. Agric. Food Chem. 46:1510-1514.

Zhang, Z., and J. Pawliszyn. 1993. Headspace solid-phase microextraction. Anal. Chem. 65:1843-1852. 